Biological and Clinical Sciences Research Journal

ISSN: 2708-2261

www.bcsrj.com

DOI: https://doi.org/10.54112/bcsri.v2021i1.76

Biol. Clin. Sci. Res. J., Volume, 2020: 76

Review Article

\title{
ANTIBACTERIAL AND ANTIOXIDANT ACTIVITY OF KIWI FRUIT
}

\author{
SIDDIQUE $A^{1 *}$, IDRESS $\mathrm{N}^{1 *}$, KASHIF $M^{1}$, AHMAD $R^{1}$, ALI $A^{1}$, ALI I ${ }^{2}$, SIDDIQUA $A^{3}$, JAVIED MA $^{1}$ \\ ${ }^{1}$ Institute of Molecular Biology and Biotechnology, The University of Lahore, Lahore, Pakistan \\ ${ }^{2}$ Department of Microbiology and Molecular Genetics, University of Okara, Pakistan \\ ${ }^{3}$ Department of Biotechnology, GCU Faisalabad, Pakistan \\ Corresponding author: siddaysha27@gmail.com, nimijutt729@gmail.com
}

(Received, $17^{\text {th }}$ December 2020, Revised $16^{\text {th }}$ July 2021, Published $19^{\text {th }}$ July 2021)

\begin{abstract}
The kiwi fruit has been drawing attention and a great deal of interest because of its health benefits. It is consumed in its natural form, while it is being presented in processed form by the food industry such as sweets, ice creams, frozen juice or pulp, and many other byproducts. The peel of kiwi fruit which is a byproduct of fruit is still under exploration, but it has raised much interest in this by-product because this has many bioactive molecule contents in it such as phenolic compounds. Kiwi fruit has shown antimicrobial activity apart from the antioxidant activity against many pathogenic bacteria i.e. Escherichia coli, Pseudomonas aeruginosa, Staphylococcus aureus, and Listeria monocytogenes as well as fungi like Penicillium funiculosum, Aspergillus niger, Aspergillus versicolor and Aspergillus ochraceus. With the presence of antibacterial, antifungal, and antioxidant activities in kiwi fruit, it may be used as a potential medicinal fruit.
\end{abstract}

Keywords: kiwi fruit, antibacterial, antifungal, antioxidant, polyphenols

\section{Introduction}

The kiwi fruit (Actinidia deliciosa $\mathrm{L}$.) was originated from river Yangtze in the valley of Northern China and in the province of Zhejiang on eastern China's shore (Garcia et al. 2011). China is the major producer in the world due to its highest production of kiwi fruit which estimates around about 1.06 million tons annually (Huang et al., 2003). In the whole world, around about 70 species of kiwi fruit are found but only A. deliciosa (green kiwifruit) and Actinidia chinensis (golden kiwifruit) are commercially processed (Huang et al., 2001). In an industrial production a large amount of seeds and peels is discarded away because they only use pulps and juices of fruits. There is little exploration regarding usage of these byproducts, however, in some studies it is described that these byproducts are good source of many other bioactive compounds such as carotenoids, terpenoids and polyphenols(SantanaMéridas et al., 2012). Seeds and peels have many biological activities like antioxidant activities (Talukder et al., 2016), antimicrobial (Soquetta et al., 2016), anti-inflammatory (LLi et al., 2014) and antidiabetic activity (Asghar, 2013) and many other activities that are extensively associated with these biological and chemical compounds, especially these are associated with polyphenols (Latocha et al., 2010). So, these factors give us a lead to consider that these residues which are obtained from industrial units and agriculture systems, which have an added value and have rich contents like bioactive molecules which were little explored in past (Folletta et al., 2019).

There are 60 species of plant genus Actinidia, and according to literature, this Kiwi fruit is native to north-central china. In the beginning of 20th century the commercialization of kiwi fruit was started and the cultivation of Hayward was the most recognized one and commercialized one (Asghar, 2013; Folletta et al., 2019). There is a high conservation capacity in Kiwi fruit, as at the temperature of $0{ }^{\circ} \mathrm{C}$ it can be stored for many months without decline in quality of fruit (Krupa et al., 2011). According to nutritional point of view kiwi fruit is enriched with dietary fiber, vitamins such as (A, C and E), minerals as well as phenolic compounds (Latocha et al., 2010; Zhu et al., 2013). The peel of kiwi fruit which is a byproduct of fruit is still under exploration, but it has raised much interest in this by product because this has much bioactive molecule contents in it such as phenolic compounds i.e. $1273 \mathrm{mg} / 100 \mathrm{~g}$ when compared with other fruits' peel for example apple peel (329 $\mathrm{mg} / 100 \mathrm{~g}$ ) and orange peel $(473 \mathrm{mg} / 100 \mathrm{~g}$ ) (Asghar, 2013; Wojdyło et al., 2017). It has been found that the residues of kiwi fruits can be considered as these are rich source for added value compounds that are of great for several industrial sectors. There are many studies in literature which explains the kiwi fruit; hence it is considered that there is still much need of

[Citation: Siddique, A., Idrees, N., Kashif, M., Ahmad, R., Ali, A., Ali, I., Siddiqua A., Javied M.A. (2021). Antibacterial and antioxidant activity of Kiwi fruit. Biol. Clin. Sci. Res. J., 2021: $76 . \quad$ doi: https://doi.org/10.54112/bcsrj.v2021i1.76] 
research to ensure the complete utilization of kiwi fruits' bioactivity (Wang et al., (2018).

Dias et al., (2020) found that by valorization the application, exploration of food byproducts can be done, hence, Food waste can be reduced, and in this regard more studies are needed. So keeping in view his point, present study aimed at exploring bioactive compounds' properties in 2 different kiwi fruit varieties i.e. Actinidia spp (red kiwi pulp) and Actinidia deliciosa cv. "Hayward" (green kiwi pulp). Keeping in view boosting the application of kiwi fruit in food industries, chemical properties of pulp and peel were assessed, and being evaluated regarding anti-microbial, anti-inflammatory, antioxidant cytotoxic activities etc. To find the antibacterial activity, kiwi peel along with its pulp were dissolved within water which has concentration of $10 \mathrm{mg} / \mathrm{ml}$. And this antibacterial activity of kiwi pulp and peel was assessed through previously used methods (Soković et al., 2010) using Escherichia coli as well as Enterobacter cloacae (human isolate) which are actually gram negative bacteria, on the other hand Listeria monocytogenes and Bacillus cereus (food isolate), have also been used which are gram positive bacteria. Minimum inhibitory concentration and minimum bactericidal concentrations were determined and ampicillin \& streptomycin were used as a positive control. By following the protocols described by Soković and van Griensven (2006) antifungal activity was observed, by using four different species of fungi: Penicillium funiculosum, Aspergillus niger, Aspergillus versicolor and Aspergillus ochraceus. Ketoconazole was used as positive control and minimum inhibitory conc. And minimum fungicidal concentrations were determined. Amina et al., (2019) discovered that polyphenols and flavonoids were abundant in pericarp of kiwi fruit as compare to the flesh of the fruit, as these contents were $12.8 \mathrm{mg} / \mathrm{g}$ for polyphenols and $2.7 \mathrm{mg} / \mathrm{g}$ for flavonoids. According to LC/MS analysis, it was found that epigallocatechin, quercitin and catachin contents that were main polyphenols in kiwi fruit were higher in peel of fruit than the flesh of kiwi fruit $(P<0.05)$. As compare to the flesh, the antioxidant activity and anti-bacterial activity of peel was significantly higher. On the other hand, during proliferation of the HepG2 cells, that were time and dose dependant, were inhibited by polyphenols in kiwi fruit. After 72 hours, the $\mathrm{IC}_{50}$ for peel and flesh polyphenols of kiwi fruit was $170 \mu \mathrm{g} / \mathrm{mL}$ and 291 $\mu \mathrm{g} / \mathrm{mL}$ respectively. Hence it was proved that the peel of kiwi fruit has high polyphenols and flavonoids and it exerts more antibacterial, antioxidant, and anticancer activity than the flesh of the fruit. So, this study strengthens the scientific evidence for kiwifruit development that has excellent bioactivity in its peel.

It has been discovered that the post-harvest commodities have high amount of active elements, which has many physiological and biological benefits for human beings, especially fruits and vegetables. Due to remarkably significant vitamin C contents, balanced nutritional composition i.e. minerals, dietary fibers, and any other health beneficial metabolites, kiwifruit is an economic crop (Liu, J. et al., 2018). Actinidia chinensis specie is now being cultivated in many countries like including the China and this has attracted many researchers in past decade (Montefiori, M., et al., 2005). Studies till date regarding A. chinensis are mainly focused on the bioactivity, genome of kiwi fruit, bioactive constituents and factors which are affecting the quality of fruit and other factors in fruit flesh (Huang et al, 2013; Kwanhong et al., 2017; Zhang et al., 2014). In many studies, thin-layer chromatography, ultra-high performance liquid chromatography, and high performance liquid chromatography are being used for characterization and isolation of phenolic compounds in the flesh of kiwi fruit (SunWaterhouse et al., 2009; Pinelli et al., 2013).

Kiwi fruit has shown antimicrobial activity apart from antioxidant activity against many pathogenic bacteria i.e. Escherichia coli, Pseudomonas aeruginosa, Staphylococcus aureus and Listeria monocytogenes (Kichaoi et al., 2015). For exploring the health benefits of kiwi fruit flesh on human health, it has been remained in research for many decades. Specially, the kiwifruit peel is used in the citric acid and alcohol production with the process of solid state fermentation due to its commercial potential. Indeed many other fruits' peel is abundant in phenolic and other bioactive compounds than this corresponding fruit's flesh (Fattouch et al, 2008). However, there are only 2 papers which are reporting on the polyphenol profile of kiwi fruit' peel (Dawes et al., 2008). Till now, study has described the differences between the polyphenol compounds and the bioactivity of flesh and peel of kiwi fruit. According to the results, scientists found that this kiwi fruit is an excellent anti-microbial agent against many microbes like Streptococcus pyogenes with a M.I.C (minimum growth inhibitory concentrations) $0.731 \mathrm{mg} / \mathrm{ml}$ and Staphylococcus aureus with a M.I.C of $3.125 \mathrm{mg} / \mathrm{ml}$. It has been found by researchers there is no specific or significant difference between vancomycine and kiwi fruit extracts in term of their anti-microbial activity against Staphylococcus aureus it means both of these

[Citation: Siddique, A., Idrees, N., Kashif, M., Ahmad, R., Ali, A., Ali, I., Siddiqua A., Javied M.A. (2021). Antibacterial and antioxidant activity of Kiwi fruit. Biol. Clin. Sci. Res. J., 2021: 76. doi: https://doi.org/10.54112/bcsrj.v2021i1.76] 
have comparable antioxidant antibacterial activity. On the other hand, scientists also found that though kiwi fruit is an effective anti-agent against microbes specially $S$. pyogenes and $S$. aureus, but it is inferior to vancomycine which is an active antibiotic against above said microbes. So, kiwi fruit extracts can be understood the potential alternative to this antibiotic vancomycine in treating Staphylococcus aureus or S. pyogenes. However, lower activity is shown by kiwifruit extracts in treating $\mathrm{S}$. pyogenes as compared to the vancomycine (Barario et al., 2019).

He et al. (2019) found that extracts from all parts of kiwi fruit including pulp, skin, stems and seed have antibacterial activity against many bacteria like Streptococcus pyogenes, Staphylococcus aureus, Klebsiella pneumonia, Escherichia coli, Pseudomonas aeruginosa, S. faecalis, Proteus mirabilis, and Salmonella typhi. With the MIC valueof $8 \& 4 \mu \mathrm{g} / \mathrm{ml}$, the pulp and skin of kiwi fruit showed maximum inhibition activity against $S$. pyogenes and $S$. aureus, but minimum inhibition activity was shown against $S$. faecalis, $K$. pneumonia, $S$. typhi, P. mirabilis, E. coli and P. aeruginosa with MIC value that ranged from $16-128 \mu \mathrm{g} / \mathrm{ml}$. on the other hand, with the MIC value of 64 and $32 \mu \mathrm{g} / \mathrm{ml}$, the extracts from stem ad leaves inhibited $S$. pyogenes and $P$. aeruginosa. With the MIC valueof 1 and $8 \mu \mathrm{g} / \mathrm{ml}$, the extracts from seed showed maximum bacteriostatic activity against selected bacterial strains (Basile et al., 1997; Deng et al. 2013).

A significant bactericidal effect was shown against Bacillus cereus, Shigella flexneri, B. subtilis, Salmonella typhi and bacteriostatic against $B$. thurigiensis, by polyphenols extracted from seeds of A. cinensis. Deng et al. (2013) found that the activity of extracts from kiwi fruit that contains polyphenols exerts more antibacterial. He et al. (2019) found that due to health benefits, economic and nutritional values, Chinese kiwi fruit and its related products are gaining popularity throughout the whole world. Kiwi fruit is the good source of carbohydrates, sugars, vitamin $\mathrm{C}$, minerals and phenolic compounds. Especially, kiwi fruit possess vitamin $\mathrm{C}$ and minerals $\mathrm{K}$ in it. Flavonoids and organic acids are the phenolic compounds that are present in kiwi fruit, a variety of phenolic compounds are present in flesh, leaves, peel and roots of kiwi fruit. Tri-terpenoids which are characterized through 12-en-28-oic acids of ursane and oleanane types, are the major compounds found in roots of kiwi fruit. In roots and flowers of $A$. chinensis, the major and dominant volatile compounds were alcohols, esters, straight chain alkenes and terpenes.
As proved from many in vivo ad in vitro studies, these biochemical compounds reside in kiwi fruit with many sensory qualities like pharmacological properties and nutritional properties. From these crude extracts or fractions or isolated compounds, the claimed bioactivities were immunoregulatory, hypolipemic, antibacterial, anti-inflammatory, and antioxidant, antitumor, ant diabetic and protective effects from cardiovascular diseases. Especially, the claimed biochemical activities like immunoregulatory, antioxidant and anti-tumor were due to the polyphenols, polysaccharides, flavonoids, triterpenoids, vitamin $\mathrm{C}$ and unsaturated fatty acids. So these findings show that this miraculous fruit may prove as an excellent agent for treatment for oxidative stress, aging and pathologies related to cancer. There are also many opportunities for utilization, better protection and better development for human consumption and usage of kiwifruit. For safe human consumption, studies should be conducted on toxicity analysis, quantitative and qualitative metabolite research, inhibitory activities by cytochrome P450, clinical studies and standardized and effective quality standard building. On the other hand, attenuation and synergism effects, molecular mechanism and in vivo mechanism that are responsible for different biological and metabolic behavior of many ingredients, studies should be conducted on them.

It was discovered that a little studies supported $A$. chinensis cultivars, hence, more confirmative studies should be conducted for the verification of their health benefits. For the effective utilization of kiwi fruit, the parts of kiwi plant other that fruit like roots, leaves, stem and twigs should be explored. Similarly, more studies are needed on harvest and post-harvest for avoiding the damage caused by mildew, soft rot, chilling damage and decrease in chemical profile of kiwi fruit and for improving the chemical properties during storage of kiwi fruit. Antioxidant activities of the bioactive compounds of A. chinensis have been studied many times in in vivo and in vitro assay. The in vitro assay consisted of biological assay and chemical assay like ABTS, FRAP, ORAC HO, DPPH, lipid oxidation and oxidative stress caused by $\mathrm{H}_{2} \mathrm{O}_{2}$ (Chai et al., 2014; Deng et al., 2018; Hwang et al., 2017; Lee et al., 2015). While the in vivo assay was consisting on ALT, AST, SOD, GSH, lipid oxidation and oxidative damage to DNA (Hwang et al., 2017; Iwasawa et al., 2011; Sun et al., 2017; Wang et al., 2018). The results indicated that to various extents kiwi fruit is a good source of antioxidants, antibiotics and many bioactive compounds. Antioxidant properties are much

[Citation: Siddique, A., Idrees, N., Kashif, M., Ahmad, R., Ali, A., Ali, I., Siddiqua A., Javied M.A. (2021). Antibacterial and antioxidant activity of Kiwi fruit. Biol. Clin. Sci. Res. J., 2021: 76. doi: https://doi.org/10.54112/bcsrj.v2021i1.76] 
attributed to flavonoids, polyphenols, the unsaturated fatty acids and vitamin $C$. In addition; different antioxidants properties were shown by different parts of kiwi fruit plant, extraction method of these bioactive compounds and genetic makeup and diversity of plant. Followed by the pulp and core of kiwifruit, the peel of the fruit shown maximum antioxidant activity. Due to the presence of vitamin C in pulp, antioxidant activity was shown and this antioxidant activity in peel was mainly dependent on the presence of polyphenols (Zhang et al., 2016). Deng et al. (2018) found that the kiwi fruit cultivars like Hongyang and Hort 16A were rich in attractive materials such as unsaturated fatty acids and this showed scavenging capacity for FRAP, DPPH, HO and ORAC with IC50 of $3.3 \mathrm{mg}$ Trolox $/ \mathrm{kg}(32.4$ $\mathrm{mg} / \mathrm{ml}, 1.04 \mathrm{mg} / \mathrm{ml}), 1.69 \mathrm{mg}$ Trolox $/ \mathrm{kg}$, and 107.3 $\mathrm{mg}$ Trolox/kg $(31.4 \mathrm{mg} / \mathrm{ml}, 1.09 \mathrm{mg} / \mathrm{ml}), 1.99 \mathrm{mg}$ Trolox/kg, respectively.

Fresh and freeze-dried kiwifruit variety (Hort 16A) was having radical scavenging capacities and these were rich in flavonoids and polyphenols for ORAC, DPPH, ABTS were 98.3, 8.8, 8.8 and 40.3, 5.0, 6.0 mg VCE/g accordingly (Hwang et al., 2017). On the other hand the scavenging capacity for Cuiyu and Red sun which were rich in polyphenols and flavonoids for FRAP, ORAC, DPPH, ABTS were $1.50,10.78,1.01,1.35$ and $1.28,8.87,0.9,1.32 \mathrm{mg}$ VCE/g accordingly (Wang et al., 2018; Hwang et al., 2017). On oral administration of kiwi fruit, $t$ protected lymphocytes from oxidative damage and it also inhibited the lipid oxidation in mice, on the other hand it decreased AST and ALT levels and increased the GSH and SOD levels in patients. Hence, it is confirmed that kiwi fruit is is residing antioxidant activity, therefor, appropriate extraction method, proper screening of plant parts and genotypes of the plant is required to maximize and enhance antioxidant activities of A. chinensis (Hwang et al., 2017; Sun et al., 2017).

It was discovered by Zhang et al., (2018) for checking the antiviral activity of kiwi fruit (A. chinensis) some bioactive compounds were isolated from roots of the plant and the findings of the research showed that spathodic acid-28-O- $\beta$-Dglucopyranoside and 5-methoxy-coumarin-7- $\beta$-Dglycosidase was having high anti-phytoviral activity along with inactivation effect which ranged from $42.56 \%$ to $56.76 \%$ which was higher than other compounds like ningnanmycin which was used as control. The extract from roots of A. chinensis removed the DPPH, wich is a superoxide anion and it also inhibited the HO (hydroxyl radicle) production (Yang and He, 2012). Olatunde et al. (2019) found that some pure compounds and extractions from $A$. chinensis' roots showed biochemical properties such as antiviral, antioxidant, detoxifying agent, homeostatic agent, and antidiuretic, antitumor, antihepatitis which were in agreement to the folkloric stories for usage of A. chinensis as a medicinal plant. Studies and researches showed that triterpenoids are fixed and bound in the roots of kiwi fruit which are mainly responsible for the anticancer property of kiwifruit. To verify this hypothesis, more researches and analysis should be carried out. For example more biological analysis of A. chinensis and isolation of biochemical compounds from roots should be carried out. In vivo and in vitro analysis of antitumor efficacy should be judged for providing the mechanism and evidences to drug candidates and for the development of new drug discovery.

There are fifty four species of Actinidiaceae which are evenly distributed in different province of china (Liang et al., 2007; Datson et al., 2011). It was found that family of kiwi fruit i.e. Actinidiaceae is rich in biochemical compounds like flavonoids, triterpenoids, alkaloids, anthraquinons, polysaccharides, organic acids and steroids (Fu et al., 2010; Lai et al., 2007; Zhou et al., 2010). A. chinensis' roots which are often recognized as tengligen are being used as folklore medicine for the cure of gastric cancer, liver cancer and esophagus cancer (Song 2001; Jiangsu New Medical college 1977 \& 1986; Wang, L., et al., 2010; Huo et al., 2013; Cheng et al., 2015). In addition, kiwi fruit is also being used a hemostatic, anti-hepatitis, antidiuretic and detoxifying agent, because tengligen which are the roots of A. chinensis is rich in biochemical compounds (Chang et al., 2005; Lahlou et al., 2001; Lai et al., 2007; Yutaka et al. 1992) which induces a broad spectrum biochemical activity as discussed earlier.

Like China, Italy and Chile, Actinnidia chinensis L., (Syn. Actinidia deliciosa) is a commercially grown crop in New Zealand (Ferguson and Huang 2007; Lahlou et al., 2001; Nishiyama 2007). In India, due to exotic introduction of kiwi fruit, the area under cultivation of this crop is very low. With the help of development support and extensive research on kiwifruit, the cultivation of above said crop has been extended in hills of Arunachal Pradesh, Jammu Kashmir and Himachal Pradesh. Due to availability of many biochemical compounds in peel which leads to distinct flavor of the fruit, Kiwi fruit is often consumed as fresh fruit (Atkinson and Macrae, 2007). The vitamins and minerals present in fruit often affect the appearance and nutritional values of the kiwi fruit, whereas, the taste of the fruit is

[Citation: Siddique, A., Idrees, N., Kashif, M., Ahmad, R., Ali, A., Ali, I., Siddiqua A., Javied M.A. (2021). Antibacterial and antioxidant activity of Kiwi fruit. Biol. Clin. Sci. Res. J., 2021: 76. doi: https://doi.org/10.54112/bcsrj.v2021i1.76] 
generally influenced by the sweetness, volatile compounds and acidity of the fruit. For quantifying the acid contents of fruit, generally two methods are used i.e. titratable acidity (TAD) and initial $\mathrm{pH}$. Actual and Immediate acidity (actual hydrogen ion concentration in solution) is being provided by the magnitude of $\mathrm{pH}$. Total or potential acidity which includes the total number of acid molecules is being indicated by the titratable acidity. The molecules which are totally soluble in aqueous sample are called as soluble solid contents (SSC). And this SSC value is used for indicating the sweetness of kiwi fruit in commercial standards (Crisosto and Crisosto, 2001). Soluble solid contents (SSC) are being measured as unit of Brix and it is defined as percent sugar by weight. SSC value indicates the eating quality of the ripened kiwi fruit. The flavor quality is related to the ratio of sugar and organic acids present in kiwi fruit and also it indicates the optimum time for harvesting kiwi fruit (Burdon et al. 2004).

Health related attributes of kiwi fruit is the presence of Ascorbic acid in it (Ferguson and Huang, 2007), presence of flavonoids (Atkinson and Macrae 2007) and polyphenols (Sheng et al., 2005). In traditional medicine, kiwi fruit is being used for the cure of many diseases like stomach, liver and lungs cancer (Yang, 1981). Some studies shown that cancer cell growth is inhibited by the extracts obtained from the kiwi fruit (Song, 1984) and in in-vitro assay cells are being protected from oxidative DNA damage (Beever, et al., 1990; Collins et al., 2001; Lahlou et al., 2001). Antioxidants have become an important topic in modern researches they are not naturally produced on human body hence they should be consumed from some artificial sources or diet like kiwi fruit. Hence antioxidants are the substances which at low concentrations prevent or delay the oxidation of the substrate which is happening in chain reaction (Beever, et al., 1990; Halliwell and Whiteman 2004). The quality of the kiwi fruit is determined by its low Kcal contents in fruit (Tavarini et al., 2008), and high amount of phytochemicals and antioxidants (Tomas et al., 1997), such as polyphenol compounds (Park, et al., 2009), and ascorbic acid (Lahlou et al., 2001; Nishiyama, et al., 2004). The concentration of ascorbic acid has been found significantly influenced on harvest time (Park, et al., 2009). In kiwi fruit, the concentration of ascorbic acid varies from 37-200 mg 100g-1fw (Lintas et al., 1991; Selman, 1983), and this ascorbic acid concentration is higher than lemon (Cioroi, 2007), peach fruit and apple (Beever, et al., 1990); however this concentration is also effected from storage conditions (Esti, et al., 2002). Total antioxidant capacity and polyphenol contents are affected from harvest time, fruit ripening stage, storage conditions and green pruning (Tavarini et al., 2008; Gullo et al., 2013).

\section{Conflict of interest}

The authors declared absence of conflict of interest.

References

Aamina, A., Ting. L., Tanzeela, N., Daoyuan, R., Xichuan, Z., Yaxing P. and, Xingbin Y. (2019). Antioxidant, antimicrobial, and antiproliferative activitybased comparative study of peel and flesh polyphenols from Actinidia chinensis. Food \& Nut. Res. 63: 1577.

Asgar, A. (2013). Anti-diabetic potential of phenolic compounds: a review. Int. J. Food Prop. 16, 91-103.

Atkinson, R.G., and E.A. Macrae. (2007). Kiwifruit. In: Pua EC, Davey MR (ed) Transgenic Crops V. Springer Berlin Heiderberg; 60:329-346.

Barairo, J.D.I., C. L. Castillo, T. C. Jr. Francisco, D. E. S. Patrick, and Jan.M. Aldrin. (2019). Antibacterial Effect of Kiwi Fruit Extract (Actinidia chinensis) to Streptococcus pyogenes and Staphylococcus aureus. LPU-St. Cabrini Journal of Allied Medicine. 3: 2.

Basile, A., Vuotto, M.L., Violante, U., Sorbo, S., Martone, G., and Castaldo- Cobianchi, R. (1997). Antibacterial activity in Actinidia chinensis, Feijoa sellowiana and Aberia caffra. Inter. J. Antimicrob. Ag. 8, 199-203.

Beever, D.J. and G. Hopkirk. 1990. Fruit development and fruit physiology in kiwifruit science and management. Warrington I.J., Weston G.C., eds., Ray Richards, Auckland. pp. 97-126.

Burdon, J., McLeod, D., Lallu, N., Gamble, J., Petley, M., Gunson, A. (2004). Consumer evaluation of "Hayward" kiwifruit of different at-harvest dry matter contents. Postharvest Biol Technol. 34: 245-255.

Chai, W. M., Shi, Y., Feng, H. L., Xu, L., Xiang, Z. H., Gao, Y. S., et al. (2014). Structure characterization and antityrosinase mechanism of polymeric proanthocyanidins fractionated from kiwifruit pericarp. J. Agric. Food Chem. 62, 6382-6389.

Chang, J., Case, R. (2005) Cytotoxic phenolic constituents from the root of Actinidia chinesnsis. Planta Med 71: 955-959.

Cheng, Q.L., Li, H.L., Huang, Z.Q., Chen, Y.J., Liu, T.S. (2015) 2beta, 3beta, 23-Trihydroxy-urs-12ene-28-olic acid (TUA) isolated from Actinidia chinensis Radix inhibits NCI-H460 cell proliferation by de-creasing NFkappaB expression. Chem Biol Interact 240: 1-11. 
Cioroi, M. (2007). Study on L-Ascorbic acid contents from exotic fruit. Cercetari Agronomice in Moldva, XXXX 1:23-7.

Collins, B.H., A. Horska, P.M. Hotten, C. Riddoch and A.R. Collins. (2001). Kiwi fruit protects against oxidative DNA damage in human cells in vitro. Nutr. Cancer 39:148-153.

Crisosto, C.H. and G.M. Crisosto. (2001). Understanding consumer acceptance of early harvested 'Hayward' kiwifruit. Postharvest Biol Technol. 22:205-213

Datson P.M. and A.R. Ferguson (2011). Actinidia, Wild Crop Relatives: Genomic and Breeding Resources. Tropical and Subtropical Fruits 120.

Dawes, H.M. and J.B. Keene (1999) Phenolic composition of kiwifruit juice. J. Agri. Food Chem. 47 (6):2398-2403.

Deng, J. J., H. X. Yang, D. D. Fan, W. Cao and Y. E. Luo (2013). Antibacterial activities of polyphenolic extract from kiwi fruit (Actinidia chinensis Planch.) seeds. J. Pure Appl. Microbio. 7, 491-494.

Deng, J. J., Q. Q. Liu, Q. Zhang, C. Zhang, D. Liu, and D. D. Fan (2018). Comparative study on composition, physicochemical and antioxidant characteristics of different varieties of kiwifruit seed oil in China. Food Chem. 264, 411-418.

Dias, M., Caleja, C., Pereira, C., Calhelha, R.C., Kostic, M., Sokovic, M., Tavares, D., José Baraldi, I., Barros, L., C.F.R.and Ferreira, I. (2020). Chemical composition and bioactive properties of byproducts from two different kiwi varieties, Food Research International. 127, 108753

Esti, M., L. Cinquanta, F. Sinesio, E. Moneta. And M. Di-Matteo. (2002). Physicochemical and sensory fruit characteristics of two sweet cherry cultivars after cool storage. Food Chem. 76: 399-405.

Fattouch, S., Caboni, P., Coroneo, V., Tuberoso, C., Angioni, A., Dessiet, S., et al. (2008). Comparative analysis of polyphenolic profiles and antioxidant and antimicrobial activities of Tunisian pome fruit pulp and peel aqueous acetone extracts. J Agri Food Chem 56:10841090.

Ferguson, A.R., Huang, H.W. (2001). Genetic resources of kiwifruit: domestication and breeding. Hort Rev. 33: 1-121.

Folletta, P.A., Jamieson, L., Hamilton, L. \& Wall, M. (2019). New associations and host status: Infestability of kiwifruit by the fruit fly species Bactrocera dorsalis, Zeugodacus cucurbitae, and Ceratitis capitata (Diptera: Tephritidae). Crop Protection, 115, 113-121.

Fu, W.W., Tan, C.H., Lu, L.L., Meng, X.X., Luo, H.F., Zhu, D.Y. (2010). Chemical constituents from the root of Actinidia deliciosa. Chin J Nat Med 8: 247- 249.

Garcia, C.V., Quek, S.Y., Stevenson, R.J., Winz, R.A. (2012). Kiwifruit flavour: a review. Trends Food Sci Technol 24 (2):82-91.

Gullo, G., V. Branca, A.G. Dattola, R. Zappia and P. Inglese. (2013). Effect of summer pruning on some fruit quality traits in Hayward kiwifruit. Fruits. 68: 315-22.

Halliwell, B., Whitemann, M. (2004). Measuring reactive species and oxidative damage in vivo and in cell culture: how should you do it and what do the results mean? Br J Pharmacol. 142: 231-255.

He, X., Fang, J., Chen, X., Zhao, Z., Li, Y., Meng, Y. and Huang, L. (2019) Actinidia chinensis Planch.: A Review of Chemistry and Pharmacology. Front. Pharmacol. 10:1236.

Huang, H., Ferguson, A.R. (2001). Review: kiwifruit in China. N Z J Crop Hortic Sci. 29 (1):1-14.

Huang, H., Ferguson, A.R. (2003). Kiwifruit (Actinidia chinesis and A. deliciosa) plantings and production in China. $N$ Z J Crop Hortic Sci 31(3):197-202.

Huang S, Ding J, Deng D, Tang, W, Sun H, Liu D, et al. (2013). Draft genome of the kiwifruit Actinidia chinensis. Nature Commun, 4:2640.

Huang, Z. Y., Li, J., Zhang, J. F., Gao, Y. Y., and Hui, G. H. (2017). Physicochemical properties enhancement of Chinese kiwi fruit (Actinidia chinensis Planch.) via chitosan coating enriched with salicylic acid treatment. J. Food Meas. Charact. 11, 184-191.

Huo, J., Qin, F., Cai, X., Ju, J., Hu, C., et al. (2013) Chinese medicine formula "Weikang Keli" induces autophagic cell death on human gastric cancer cell line SGC-7901. Phytomedicine 20: 159-165.

Iwasawa, H., Morita, E., Yui, S., and Yamazaki, M. (2011). Anti-oxidant effects of kiwi fruit in vitro and in vivo. Biol. Pharm. Bull. 34, 128134.

Jiangsu New Medical College (1977). The Dictionary of Chinese Traditional Medicine. Shanghai, Shanghai Science \& Technology Press 2210.

Jiangsu New Medical College (1986). The Dictionary of Chinese Traditional Medicine. Shanghai Press of Science and Technology 662- 664

Kichaoi, A.E., El-Hindi, M., Mosleh, F., Elbashiti, T.A. (2015). The antimicrobial effects of the

[Citation: Siddique, A., Idrees, N., Kashif, M., Ahmad, R., Ali, A., Ali, I., Siddiqua A., Javied M.A. (2021). Antibacterial and antioxidant activity of Kiwi fruit. Biol. Clin. Sci. Res. J., 2021: $76 . \quad$ doi: https://doi.org/10.54112/bcsrj.v2021i1.76] 
fruit extracts of Punica granatum, Actinidia deliciosa and Citrus maxima on some human pathogenic microorganisms. Am Int $\mathrm{J}$ Biol 3(2):63-75.

Krupa, T., Latocha, P. \& Liwinska A. (2011). Changes of physicochemical quality, phenolics and vitamin $\mathrm{C}$ content in hardy kiwifruit (Actinidia arguta and its hybrid) during storage. Scientia Horticulturae, 130, 410-417.

Kwanhong, P., ByungSeon, L., JinSu, L., Lee, J.S., Park, H.J., Choi, M.H. (2017). Effect of 1-MCP and temperature on the quality of red-fleshed kiwifruit (Actinidia chinensis). Korean J Hortic Sci, 35 (2):199-209.

Lahlou, E.H., Hirai, N., Kamo, T., Tsuda, M., Ohigashi, H. (2001) Actinidic acid, a new triterpene phytoalexin from unripe kiwi fruit. Biosci Biotechnol Biochem 65: 480-483.

Lai, Y., Xu, D. (2007) Study on the chemical structure from the roots of Actinidia deliciosa. J Chin Med Mater 30: 166-168.

Latocha, P., Krupa, T., Wołosiak, R., Worobiej, E. \& Wilczak, J. (2010). Antioxidant activity and chemical difference in fruit of different Actinidia sp. Int. J. Food Sci. Nutr. 61 (4), 381394.

Lee, I., Lee, B. H., Eom, S. H., Oh, C. S., Kang, H., Cho, Y. S., et al. (2015). Antioxidant capacity and protective effects on neuronal PC-12 cells of domestic bred kiwifruit. Korean J. Hortic. Sci. Technol. 33, 259-267.

Li, W., Sun, Y.N., Yan, X.T., Yang, S.Y., Kim, S., Chae, D., Hyun, J.W., Kang, H.K., Koh, Y.S., \& Kim, Y.H. (2014). Anti-inflammatory and antioxidant activities of phenolic compounds from Desmodium caudatum leaves and stems. Arch. Pharm. Res. 37, 721-727.

Liang J, Wang X, Zhen H, Zhong Z, Zhang W, et al. (2007) Study on antitumor effect of extractions from roots of Actinidia deliciosa. J Chin Med Mater 30: 1279-1282.

Lintas, C., S. Adorisio, M. Cappelloni. And E. Monastra. 1991. Composition and nutritional evaluation of kiwifruit grown in Italy. New Zeal. J. Crop Hort. 19: 341-44.

Liu, J., Huang, S., Niu, X., Chen, D., Chen, Q., Tian, L., et al. (2018). Genome-wide identification and validation of new reference genes for transcript normalization in developmental and post harvested fruits of Actinidia chinensis. Gene 645:1-6.

Montefiori, M., Tony, K.M., Costa, G., Ferguson, A.R. (2005). Pigments in the fruit of red-fleshed kiwifruit (Actinidia chinensis and Actinidia deliciosa). J Agric Food Chem 53:9526-9530.

Nishiyama I. Fruits of the Actinidia Genus. In: Advances in Food and nutrition Research, Taylor SL (ed) Academic Press. 2007; 52: 293324.

Nishiyama, I., Y. Yamashita, M. Yamanaka, A. Shimohashi, T. Fukuda. And T. Oota. (2004). Varietal difference in vitamin $\mathrm{C}$ content in the fruit of kiwifruit and other Actinidia species. $J$. Agr. Food Chem. 52: 5472-5.

Olatunde, O.Z., Yang, Y., Yong, J., Lu, C. (2019). The progress of Chemical Constituents Isolated from the Root of Actinidia chinensis Planch and their Biological Activities. J Biomed Res Rev 2(2): 12-21.

Park, Y.S., S.T. Jung, S.G. Kang, B.G. Heo, S.H. Lee, F. Toledo, P. Arancibia-Avila, J. Drzewiecki and S. Gorinstein. 2009. Radical scavenging capacity of ethylene treated kiwifruit. J. Food Biochem. 33: 674-92.

Pinelli, P., Romani, A., Fierini, E., Remorini, D., Agati, G. (2013). Characterisation of the polyphenol content in the kiwifruit (Actinidia deliciosa) exocarp for the calibration of a fruitsorting optical sensor. Phytochem Analy 24(5):460-466.

Santana-Méridas, O., González-Coloma, A., \& Vioque, R.S. (2012). Agriculture residues as source of bioactive. Phytochem. Rev. 11, 447466.

Selman, J.D. (1983). The vitamin C content of some kiwifruit (Actinidia chinensis Planch., variety Hayward). J. Sci. Food Agr. 47:401-16

Sheng, Y., Akesson, C., Holmgren, K., Bryngelsson, C., Giamapa, V., Pero, R.W. (2005). An active ingredient of Cat's Claw water extracts: Identification and efficacy of quinic acid. $J$ Ethnopharmacol. 96: 577-584.

Song, L.R., Hong, X., Ding, X.L. (2001) 'Dictionary of Modern Chinese Herbal Medicine'. People's Medical Publishing House, Beijing 2453

Song, P. (1984). Anticancer activity of Chinese kiwi fruit. Nutr Res. 6: 109-114.

Soquetta, M.B., Stefanello, F.S., Huerta, K.M., Monteiro, S.S., da Rosa, C.S., \& Terra, N.N. (2016). Characterization of physiochemical and microbiological properties and bioactive compounds, of flour made from the skin and bagasse of kiwi fruit (Actinidia deliciosa). Food Chemistry, 199, 471-478.

Sun, L. F., Li, X. F., Li, G., Dai, B., and Tan, W. (2017). Actinidia chinensis Planch. improves the indices of antioxidant and anti-inflammation

[Citation: Siddique, A., Idrees, N., Kashif, M., Ahmad, R., Ali, A., Ali, I., Siddiqua A., Javied M.A. (2021). Antibacterial and antioxidant activity of Kiwi fruit. Biol. Clin. Sci. Res. J., 2021: $76 . \quad$ doi: https://doi.org/10.54112/bcsrj.v2021i1.76] 
status of type 2 diabetes mellitus by activating keap1 and nrf2 via the upregulation of microRNA-424. Oxid. Med. Cell. Longev. 2017, 7038789.

Sun-Waterhouse, D., Wen, I., Wibisono R., Melton, M.D., Wadhwa, S. (2009). Evaluation of the extraction efficiency for polyphenol extracts from by-products of green kiwifruit juicing. Int J Food Sci Technol 44: 2644-2652. https://doi.org/10.17113/ftb.54.04.16.4497

Talukder, P., Talapatra, S., Ghoshal, N. \& Raychaudhuri, S.S. (2016). Antioxidant activity and high-performance liquid chromatographic analysis of phenolic compounds during in vitro callus culture of Plantago ovata Forsk. and effect of exogenous additives on accumulation of phenolic compounds. J. Sci. Food Agr. 96, 232-244.

Tavarini, S., E. Degl'Innocenti, D. Remorini, R. Massai. and L. Guidi. (2008). Antioxidant capacity, ascorbic acid, total phenols and carotenoids changes during harvest and after storage of Hayward kiwifruit. Food Chem.107: 282-88.

Tomas-Barberan, F.A. and R.J. Robins. (1997). Phytochemistry of fruit and vegetables. Oxford Science Publications. Oxf., UK. pp. 375.

Wang, L., Kang, C., Yang, W., Li, M., Wang, Y., et al. (2010) Experimental study on antitumor effects of extracts from Actinidia argutaor. Zhongguo Zhong Yao Za Zhi 35: 2184-2186.

Wang, Y., Li, L., Liu, H., Zhao, T., Meng, C., Liu, Z. \& Liu, X. (2018). Bioactive compounds and in vitro antioxidant activities of peel, flesh and seed powder of kiwi fruit. Food Science Technology, 53, 2239-2245. $\underline{2}$

Wang, Y., Zhao, C. L., Li, J. Y., Liang, Y. J., Yang, R. Q., Liu, J. Y., et al. (2018). Evaluation of biochemical components and antioxidant capacity of different kiwifruit (Actinidia spp.) genotypes grown in China. Biotec. Biotechnol. Equip. 32, 1-8.

Wojdyło, A., Nowicka, P., Oszmianski, J. \& Golis, T. (2017). Phytochemical compounds and biological effects of Actinidia fruits. Journal of Functional Foods, 30, 194- 202.

Yang, J.X. (1981). Chinese pharmaceuticals for cancers. Peking: General people's health Publishers. pp 121-122.

Yang, Y.J., He, H.S. (2012) Kiwi Root Extract in Vitro Antioxidant Effect Research. Food Res Dev 33: 21-24.
Yutaka, S., Kazunori, O., Noriaki, M., Tsuyoshi, Y. (1992) Triterpenoids from the fruit galls of Actinidia polygama. Phytochem 31: 2801.

Zhang, X.Y., Zhou, Y., Wei, Z.P., Shen, J., Wang, L.K., et al. (2018) Antiphytoviral toxins of Actinidia chinensis root bark (ACRB) extract: laboratory and semi-field trials. Pest Manag Sci 74: 1630-1636.

Zhang, L., Zhang, W., Wang, Q., Wang, D., Dong, D., $\mathrm{Mu}, \mathrm{H}$., et al. (2015). Purification, antioxidant and immunological activities of polysaccharides from Actinidia Chinensis roots. Int J Biol Macrooml 72:975-983.

Zhang, T., Li, C., Luo, A.W., Tang, M.L., Chen, H., Li, X.L., et al. (2016). Antioxidant activities in vitro of different fruit parts of eight kiwifruit varieties. Food Sci. 37, 88-93.

Zhou, X., Liu, Y., Tang, L., Zhang, P., Wu, J. (2010) Chemical constituents from the roots of Actinidia chinensis. Chem Nat Compd 46: 308309.

Zhu, C. H., Gong, Q., Li, J. X., Zhang, Y., Yue, J. Q., \& Gao, J. Y. (2013). Research progresses of the comprehensive processing and utilization of kiwifruit. Storage and Process, 13, 57-62.

\section{(cc) (†) 8}

Open Access This article is licensed under a Creative Commons Attribution 4.0 International License, which permits use, sharing, adaptation, distribution and reproduction in any medium or format, as long as you give appropriate credit to the original author(s) and the source, provide a link to the Creative Commons licence, and indicate if changes were made. The images or other third party material in this article are included in the article's Creative Commons licence, unless indicated otherwise in a credit line to the material. If material is not included in the article's Creative Commons licence and your intended use is not permitted by statutory regulation or exceeds the permitted use, you will need to obtain permission directly from the copyright holder. To view a copy of this licence, visit http://creativecommons.org/licen ses/by/4.0/.

(C) The Author(s) 2021

[Citation: Siddique, A., Idrees, N., Kashif, M., Ahmad, R., Ali, A., Ali, I., Siddiqua A., Javied M.A. (2021). Antibacterial and antioxidant activity of Kiwi fruit. Biol. Clin. Sci. Res. J., 2021: $76 . \quad$ doi: https://doi.org/10.54112/bcsrj.v2021i1.76] 